\title{
Nutrition challenges for the twenty-first century
}

\author{
Alan D. Dangour ${ }^{1}$ and Ricardo Uauy ${ }^{1,2}$ \\ ${ }^{1}$ Nutrition and Public Health Intervention Research Unit, London School of Hygiene and Tropical Medicine, London, UK \\ ${ }^{2}$ Public Health Nutrition Division, Instituto Nutrición y Tecnología de Alimentos, Universidad de Chile, Santiago, Chile
}

\begin{abstract}
Although progress has been made towards international goals for the eradication of hunger and malnutrition, considerable work is still required to achieve them and to respond to emerging public health nutrition challenges. The present paper outlines sixteen major inter-linked nutrition challenges recently identified by the UN Standing Committee on Nutrition. While many of the challenges relate to the nutritional needs of children and mothers, an increased emphasis on nutrition-related chronic diseases that affect later life is also evident. Promoting healthy ageing and the maintenance of physical and mental function in older age are undoubtedly major challenges for the future, and the present paper also informs on the role of nutrition, specifically $n-3$ essential fatty acids, in the prevention of cognitive decline. The importance of determining the cost-effectiveness of nutrition interventions is advocated, in order that the nutrition community can respond appropriately to global nutrition challenges.
\end{abstract}

Healthy nutrition: Nutrition challenges: Malnutrition: Ageing: Cognition

Goals set in decades prior to the end of the twentieth century to mark the progress in advancing the war on hunger and malnutrition have been partially achieved. These goals were established in the UNICEF World Summit for Children in 1990, the International Conference on Nutrition (Food and Agriculture Organization/World Health Organization, 1992), and the FAO World Food Summit in 1996. Hunger and malnutrition eradication goals were part of a broader strategy to eliminate poverty as a global scourge. In fact, a significant reduction in iodine deficiency by securing iodization of salt and a major decrease in the prevalence of clinical forms of vitamin A deficiency have been achieved as part of the efforts of the last two decades. Similarly, virtually everywhere except in sub-Saharan Africa, the prevalence of underweight and stunting of children less than five years of age has significantly declined. Despite this degree of progress, the absolute number of malnourished children continues to increase.

Policies and programmes to achieve success vary between countries; there is no single formula or combination of interventions that will work in every case. The social and economic costs of malnutrition for developing and transitional areas of the world are enormous. Investing in nutrition is well justified, not only because of the reduction in health-care expenditures, but also because of the improvement of productivity, enhanced cognitive performance and educational achievements, and their corresponding impacts on economic and social development. Moreover, as singled out by the UN Standing Committee on Nutrition Commission on Nutrition Challenges:

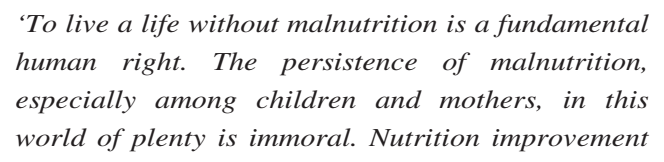

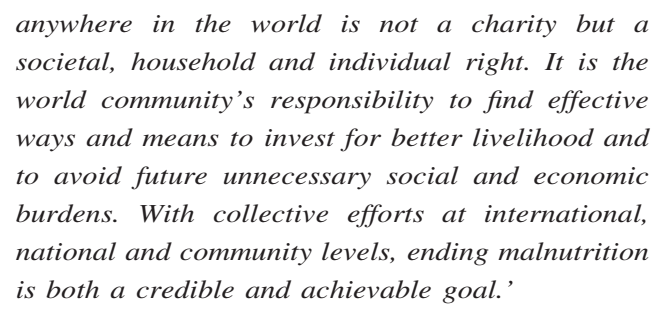

James et al. 2000

The human rights dimension of hunger and malnutrition is the ultimate goal. We need not justify the cause by the damage avoided or the loss of potential economic and social gains, but should reinforce our argument by the need to respect, protect and promote the right to safe and nutritious food. More recently, the definition of Millennium Development Goals, to be achieved by 2015 , have served to invigorate the UN system's global development agenda. The Millennium Development Goals highlight the pending agenda in terms of minimal standards for progress in global health, nutrition and development.

\section{Nutrition challenges for the twenty-first century}

The UN Standing Committee on Nutrition Commission on Nutrition Challenges (James et al. 2000) identified the following sixteen major inter-linked nutrition challenges. The first eight are part of the pending agenda, the remainder are emerging problems that will dominate the global agenda in the years ahead:

1. Some 30 million infants are born each year in developing countries with intra-uterine growth retardation, representing approximately $24 \%$ of all newborns in these 
countries. Population-wide interventions aimed at preventing fetal growth restriction and low birth weight are urgently needed.

2. There are still more than 150 million underweight preschool children worldwide, and close to 200 million stunted children. This underweight and stunting is the tip of the iceberg. Suboptimal growth may affect many more. Stunting is linked to mental impairment. At current rates of improvement, by the year 2020, approximately one billion children will be growing up stunted in their physical growth and impaired in their mental development.

3. High proportions of Asian and African mothers are undernourished: this is exacerbated by seasonal food shortages, especially in Africa. Approximately 243 million adults in developing countries are severely undernourished, judged by a BMI of less than $17 \mathrm{~kg} / \mathrm{m}^{2}$, with greater numbers with modest underweight having an impaired work capacity and a lower resistance to infection.

4. Anaemia during infancy, made worse by maternal undernutrition, causes poor brain development. Anaemia is also extremely prevalent in school children and adolescents. Maternal anaemia is pandemic, over $80 \%$ in some countries, and is associated with very high rates of maternal death.

5. Severe vitamin A deficiency is on the decline in all regions. However, sub-clinical vitamin A deficiency still affects between 140 and 250 million preschool children in developing countries, and is associated with high rates of morbidity and mortality. These numbers do not take into account vitamin A deficiency in older children and adults and thus seriously underestimate the total burden of vitamin A deficiency.

6. Evidence from both developing and industrialized countries suggests a fundamental link between maternal and early childhood undernutrition and an increased susceptibility in adult life to non-communicable diseases (NCD) such as diabetes, heart disease and hypertension. These diet-related diseases-including some forms of cancer-are already of public health significance in developing countries.

7. Overweight and obesity are rapidly increasing in all regions, affecting children and adults alike. There are approximately 250 million obese adults already and these problems are now so common in developing countries that they are dominating more traditional public health concerns such as undernutrition and infectious disease. Obesity, especially abdominal obesity promoted by early fetal and childhood undernutrition, is a major risk factor for a number of NCD, adult-onset diabetes and hypertension in particular.

8. Efforts are needed to sustain the remarkable progress made in the last decade towards universal salt iodization and the elimination of iodine deficiency disorders. Monitoring systems, quality control and sound legislation are key priorities, as well as improving outreach to isolated communities.

9. There has been an alarming rise in the number of emergency nutrition problems over the last 10 years. The numbers of refugees and internally displaced persons peaked during the crisis in the African Great Lakes Region in 1995 when there were over 18 million in sub-Saharan Africa alone. Experience has shown that when food aid deliveries are uninterrupted and humanitarian organizations have constant access to the displaced population, undernutrition rates can be kept to a minimum.

10. Physical activity is usually considered separately from nutrition, but the nutrition community now needs to have professional involvement with this issue. In the developing world, especially in rural areas, adults are engaged in high levels of physical activity which require a high level of energy intake. The ability to sustain physical work is impaired when adults are underweight. Moreover, underweight subjects are frequently sick, particularly from infectious diseases such as diarrhoea and respiratory infections.

11. By the end of 1998, there were approximately 32 million adults and 1.2 million children living with HIV/AIDS. In total, 3 million children under 15 years of age worldwide have contracted HIV since the beginning of the pandemic, $90 \%$ of whom were born in Africa. In parts of sub-Saharan Africa, HIV/AIDS is wiping out an entire generation of the most economically active people. There is evidence that transmission rates and the progression of the disease are higher in undernourished populations.

12. Zinc deficiency has recently been brought to the attention of the international community. Mild to moderate zinc deficit may be an important cause of childhood stunting. Zinc deficiency is thought to be common in children and during pregnancy throughout the developing world. Zinc may also have an important role to play in programmes designed to address common life-threatening childhood illnesses, such as lower respiratory tract infection and diarrhoea.

13. Changing food consumption patterns. Food production, processing and manufacturing have responded to mankind's inherent demand for sugary, salty and fatty foods. The culinary and industrial enhancement of the energy density of foods by adding fats and sugars is invaluable in times of need, but potentially disadvantageous in times of plenty, especially if sedentary life-styles predominate. As societies become more urban, life-styles tend to become less active and more sedentary. This set of changes, known as the nutrition transition, is a major challenge facing the world in future decades.

14. The need for enhancing food quality more than food quantity. Development plans have concentrated on increasing cereal production, but horticulture should be promoted to aid the increased vegetable and fruit consumption needed to prevent childhood blindness and limit the development of cataracts, some adult cancers and CVD. A major increase in fish and lean meat consumption in some communities, particularly in South Asia, would help prevent anaemia, promote childhood growth, enhance resistance to infection and improve maternal and fetal health. A transformation in the promotion and processing of fats to limit the rise in total fat consumption to perhaps only $20 \%$ of dietary energy in sedentary adult populations would also improve 
health. There is a clear need for a new approach to health and food policies in most parts of the world. Strategies for improving access and availability of healthy diets at affordable prices for all communities should be a key part of these policies.

15. Developing countries are now having to deal with a double burden of infectious disease, childhood mortality and undernutrition alongside diet-related NCD. As well as the obvious health effects, this double burden has very serious economic and social implications for these countries. Treatment of NCD is costly compared with public health preventive strategies. Favouring treatment rather than prevention is a mistake already made in the industrialized world. In affluent Western societies increasing income inequality is linked to increasing health disparities between the rich and poor, despite sustained economic development.

16. Promoting healthy ageing must become a major policy initiative globally. Body composition changes with age, and the decline in lean body mass leads to decreased strength and mobility, poor balance and an increased frequency of falls. Conserving muscle mass in old age is therefore a strategy for preserving strength, and is also of significance in maintaining physical activity, retarding insulin resistance and ensuring normal immune function. Preventing age-related decline in cognitive function and maintaining good eye health into older age are also both major challenges.

We have chosen to focus the final section of the present paper on the last of these challenges, namely finding nutritional means to ensure healthy ageing. This is a challenge facing developed and developing countries alike, which requires appropriate integration of available basic biological knowledge for the formulation and evaluation of nutrition interventions. Our short review will focus specifically on nutrition as a means to prevent or delay cognitive decline.

\section{Nutrition and healthy ageing}

Developing country populations are currently undergoing rapid and unprecedented changes in their age structure, resulting in considerable population ageing. While the percentage of the total population under 15 years of age will drop from its current level of 33 to $22 \%$ in 2050, the percentage aged over 60 years will more than double from 8 to $19 \%$ over the same time. The increase in the proportion of over $60 \mathrm{~s}$ in developing countries is 1.5 times faster than that projected in developed countries, and by $2050,80 \%$ of all over 60 s will be living in developing countries (United Nations, 2001).

The importance of good nutrition among older people for the maintenance of health has long been advocated, and evidence-based dietary recommendations for older people have recently been published (World Health Organization/ Tufts University, 2002). However, for a variety of functional, physiological, psychological and social reasons older people are nutritionally vulnerable and frequently consume diets that are poor in both quality and quantity. This vulnerability often results in macronutrient and micronutrient undernutrition among older people in both developed and developing countries.
As populations age, the proportion and absolute number of individuals with age-related cognitive impairment rises (Melzer et al. 1997). There has been particular interest in the hypothesis that improving the diet of older people may be able to delay the initiation, or slow the progression, of cognitive decline. Research in this area, initially aroused by a small survey demonstrating an association between blood levels of vitamins $C$ and $B_{12}$ and tests of cognitive ability (Goodwin et al. 1983), remains very active (Manders et al. 2004). The evidence from cross-sectional studies is indeed quite suggestive of a link between B vitamin (Selhub et al. 2000) and antioxidant (Haller et al. 1996; Jama et al. 1996; Perrig et al. 1997; Perkins et al. 1999) status and cognitive function in older people.

Cross-sectional surveys on this topic are common, but very few studies have looked at the longitudinal association between micronutrient status and cognitive health. Of particular note here is a recent 3-year cohort study among 2889 community-dwelling adults aged 65 years and above which showed that individuals in the highest quintile of total vitamin E intake had a $36 \%$ lower rate of cognitive decline over three years than those in the lowest vitamin E quintile (Morris et al. 2002). While this is potentially a very important finding, significant concerns have recently been raised that high-dose vitamin E supplementation may increase the severity of certain morbidities (Graat et al. 2002) and the risk of all-cause mortality (Miller et al. 2005).

Unfortunately, positive findings of associations between micronutrient status and cognitive health have not been corroborated by the results of the few clinical trials of micronutrient supplementation. Indeed, a series of Cochrane reviews has concluded that there is no evidence of an effect of thiamin (Rodriguez-Martin et al. 2001), $\mathrm{B}_{6}$ (Malouf \& Grimley, 2003), folate (Malouf et al. 2003), $\mathrm{B}_{12}$ (Malouf \& Areosa Sastre, 2003) or vitamin E (Tabet et al. 2000) supplementation on cognitive health. Various reasons behind the contradictory findings between observational and interventional studies have recently been discussed (Dangour et al. 2004; Lawlor et al. 2004). These include uncontrolled confounding in observational studies, small interventions of short duration, and the unrepresentativeness of the dietary supplements used.

Increasing awareness of genetic polymorphisms, as well as the interactions between genes and nutrients, has highlighted a further complication in such studies. For example, a recent meta-analysis reviewing the association between plasma homocysteine levels and CVD (Wald et al. 2002) focused on the additional risk to individuals with a mutation in a gene coding for an enzyme involved in folate metabolism. The mutation results in a $20 \%$ elevation in plasma homocysteine levels and a concomitantly higher risk of both IHD and deep vein thrombosis. In individuals with this mutation, folate intake must clearly be higher than normal to attain a lower risk profile.

In contrast to B vitamins and antioxidants, far less attention has been paid to other dietary factors plausibly related to cognitive health in older age, such as $n-3$ long-chain PUFA ( $n-3$ LCP). The brain is particularly rich in $n-3$ LCP such as EPA and DHA, and $n$-3 LCP have repeatedly been shown to be crucial to brain development in man (Uauy et al. 2001). Animal studies have demonstrated that ageing is associated with decreased levels of DHA in rat brains (Suzuki et al. 1989; Favrelere et al. 2000). Moreover, cognitive testing on rats 
fed on a low-DHA diet for one or more generations has demonstrated clear deficits in cognitive function in DHAdeficient rats (Suzuki et al. 1998; Lim \& Suzuki, 2000; Catalan et al. 2002). This decrease with ageing in $n-3$ LCP level in total brain lipids has also been reported in man, and it has been postulated that this decline is correlated in part with agerelated deterioration of functions of the central nervous system (Soderberg et al. 1990, 1991).

Evidence supporting the potential importance of increased fish and $n$-3 LCP consumption for good cognitive health in older age is beginning to emerge. For example, a recent cross-sectional survey has reported that higher fatty fish and $n-3$ LCP consumption is associated with a reduced risk of impaired cognitive function (Kalmijn et al. 2004). Similarly, prospective studies have demonstrated that increased fish consumption is associated with a decreased risk of dementia (Kalmijn et al. 1997; Barberger-Gateau et al. 2002) and Alzheimer's disease (Morris et al. 2003) among older people.

A clue to the role of $n-3 \mathrm{LCP}$ in preventing cognitive decline or dementia is provided by analysis of erythrocyte membrane composition among older people taking part in the Etude du Vieillissement Artérial (EVA) study (Heude et al. 2003). The study demonstrated that individuals who declined cognitively over a 4-year follow-up had a higher proportion of stearic acid in their erythrocyte membranes than those who showed no decline. Importantly, erythrocyte membrane content of total $n$-3 PUFA, and specifically DHA, was inversely associated with cognitive decline (Heude et al. 2003).

The mechanisms behind the role of $n-3$ LCP in improving vascular health outcome are beginning to be relatively well understood, and include the ability of $n-3$ LCP to inhibit hepatic triacylglycerol synthesis and, by modifying eicosanoid function, to cause vascular relaxation, a diminished inflammatory process and decreased platelet aggregation (Uauy \& Valenzuela, 2000). These actions may be extremely important in decreasing the risk of silent brain infarcts that are a cause of vascular cognitive impairment (O'Brien et al. 2003) and have been shown to be directly associated with cognitive decline (Vermeer et al. 2003).

Some very exciting recent work has focused on the protective role of DHA in the brain. In a mouse model of ischaemic stroke, two of the major causes of post-stroke neuronal injury, namely lipid peroxidation and leucocyte infiltration, appear to be inhibited by a bioactive docosanoid derived from DHA (Marcheselli et al. 2003). This docosanoid, 10-17S-docosatriene, more recently named neuroprotectin D1 (Mukherjee et al. 2004), has been shown to act potently on cultured neuronal cells to down-regulate proinflammatory gene expression (Marcheselli et al. 2003). The role of DHA in modifying gene expression was also demonstrated in a study on human fetal retinal explants, in which the presence of DHA in the growth serum was found to increase the expression of $14 \%$ of genes, while oleic acid increased gene expression by less than $0.5 \%$ (Rojas et al. 2003).

Moreover, DHA is known to protect in vitro cultured hippocampal neurons from apoptotic death (Kim et al. 2000). This latter action has been replicated among retinal pigment epithelium and has been directly linked to the effects of neuroprotectin D1 to counteract oxidative-stress triggered DNA damage, as well as up-regulate antiapoptotic, and decrease proapoptotic, protein expression (Mukherjee et al.
2004). In a mouse model of Alzheimer's disease (Tg2576), dietary DHA deficiency was shown to induce a decline in DHA content of the frontal cortex. This was associated with an increase in the fractin:actin ratio, and the accumulation of the fragmented actin (fractin) was associated with a decrease in the content of key proteins responsible for post-synaptic processing such as drebin and synapsin. Fractin accumulation correlated with a significant loss of dendritic spine formation, loss of the p85 $\alpha$ subunit of phosphatidylinositol kinase and increased oxidative damage as evidenced by increased carbonyl production. No neuronal losses were observed in the hippocampus. These structural and biochemical alterations are similar to those found in the brain of early Alzheimer's disease sufferers. Behavioural alterations, in terms of poorer shortterm memory and learning capacity, were established in the DHA-deficient animals. Supplementation of these adult mice with DHA modified brain fatty acid composition, protected them in part from the adverse biochemical effects, and resulted in improved cognitive performance (Calon et al. 2004).

\section{Conclusions}

Nutrition plays an important role in defining health and wellbeing at all stages of the life course. In past decades, nutrition was centred on optimizing growth, and preventing infectious disease morbidity, death and disability, in early life. These efforts are responsible for an increase in child survival and a corresponding increase in mean life expectancy of those born in developed and transitional countries. Much still needs to be done to address malnutrition and associated child deaths in sub-Saharan Africa and South Asia. Presently, new initiatives are being launched to prevent premature adult deaths globally. WHO, in collaboration with FAO and the UN system, has launched a global strategy based on diet, nutrition and physical activity to prevent nutrition-related chronic diseases (obesity, diabetes, myocardial infarct, stroke, hypertension, and some forms of cancer). If effective, this should lead to further improvements in adult life expectancy and to increasing numbers of people reaching older ages.

The time has come to define preventative strategies not only to avoid premature deaths, but also to preserve function in older people. This has direct implications on quality of life and on health expenditures destined for this age group. Adding healthy life years at moderate costs associated to preventive measures including dietary interventions makes more sense than increasing expenditures in intensive care in the last days of life. The challenge for nutrition scientists is now to integrate existing knowledge and further advance research on how to prevent age-related declines in neural function and vascular health, which is essential for preserving function in older age. These are by no means obligatory conditions associated to ageing; we know that micronutrient sufficiency and quality of the fat supply play key roles in preserving function. Age-related cognitive decline is by now amongst the main causes of lost disability-adjusted life years in people older than 60 years of age. An effectiveness study on DHA and EPA for the prevention of cognitive decline (the OPAL study) and a cost-effectiveness study on the role of nutrition and physical activity in preserving strength and host defences in older people (the CENEXChile study), are currently being conducted by the authors. 
Until we find cost-effective interventions to prevent cognitive decline in older people, we will continue to pay the human and social cost of our insufficient action.

\section{Acknowledgements}

The authors acknowledge grants from the UK Food Standards Agency (NO5053) and the Wellcome Trust (075219) which supported in part the preparation of the manuscript.

\section{References}

Barberger-Gateau P, Letenneur L, Deschamps V, Peres K, Dartigues JF \& Renaud S (2002) Fish, meat, and risk of dementia: cohort study. BMJ 325, 932-933.

Calon F, Lim GP, Yang F, et al. (2004) Docosahexaenoic acid protects from dendritic pathology in an Alzheimer's disease mouse model. Neuron 43, 633-645.

Catalan J, Moriguchi T, Slotnick B, Murthy M, Greiner RS \& Salem N Jr (2002) Cognitive deficits in docosahexaenoic aciddeficient rats. Behav Neurosci 116, 1022-1031.

Dangour AD, Sibson VL \& Fletcher AE (2004) Micronutrient supplementation in later life: limited evidence for benefit. J Gerontol A Biol Sci Med Sci 59, 659-673.

Favrelere S, Stadelmann-Ingrand S, Huguet F, De Javel D, Piriou A, Tallineau C \& Durand G (2000) Age-related changes in ethanoalmine glycerophospholipid fatty acid levels in rat frontal cortex and hippocampus. Neurobiol Aging 21, 653-660.

Food and Agriculture Organization/World Health Organization (1992) World Declaration and Plan of Action for Nutrition. Rome: FAO.

Goodwin JS, Goodwin JM \& Garry PJ (1983) Association between nutritional status and cognitive functioning in a healthy elderly population. JAMA 249, 2917-2921.

Graat JM, Schouten EG \& Kok FJ (2002) Effect of daily vitamin E and multivitamin-mineral supplementation on acute respiratory tract infections in elderly persons: a randomized controlled trial. JAMA 288, 715-721.

Haller J, Weggemans RM, Ferry M \& Guigoz Y (1996) Mental health: minimental state examination and geriatric depression score of elderly Europeans in the SENECA study of 1993. Eur J Clin Nutr 50, Suppl. 2, S112-S116.

Heude B, Ducimetiere P \& Berr C (2003) Cognitive decline and fatty acid composition of erythrocyte membranes - The EVA Study. Am J Clin Nutr 77, 803-808.

Jama JW, Launer LJ, Witteman JC, den Breeijen JH, Breteler MM, Grobbee DE \& Hofman A (1996) Dietary antioxidants and cognitive function in a population-based sample of older persons. The Rotterdam Study. Am J Epidemiol 144, 275-280.

James WPT, Simitasiri S, Ul Haq M, Tagwirery J, Norum K, Uauy R \& Swaminathan MS (2000) Ending malnutrition by 2020 - an agenda for change in the millennium. WHO Food and Nutrition Bulletin 21S, 1S-76S.

Kalmijn S, Feskens EJ, Launer LJ \& Kromhout D (1997) Polyunsaturated fatty acids, antioxidants, and cognitive function in very old men. Am J Epidemiol 145, 33-41.

Kalmijn S, van Boxtel MP, Ocke M, Verschuren WM, Kromhout D \& Launer LJ (2004) Dietary intake of fatty acids and fish in relation to cognitive performance at middle age. Neurology 62, 275-280.

Kim HY, Akbar M, Lau A \& Edsall L (2000) Inhibition of neuronal apoptosis by docosahexaenoic acid $(22: 6 n-3)$. Role of phosphatidylserine in antiapoptotic effect. $J$ Biol Chem 275, 35215-35223.

Lawlor DA, Davey Smith G, Kundu D, Bruckdorfer KR \& Ebrahim S (2004) Those confounded vitamins: what can we learn from the differences between observational versus randomised trial evidence? Lancet 363, 1724-1727.
Lim SY \& Suzuki H (2000) Intakes of dietary docosahexaenoic acid ethyl ester and egg phosphatidylcholine improve maze-learning ability in young and old mice. J Nutr 130, 1629-1632.

Malouf M, Grimley EJ \& Areosa SA (2003) Folic acid with or without vitamin B12 for cognition and dementia. Cochrane Database Syst Rev, CD004514.

Malouf R \& Areosa Sastre A (2003) Vitamin $B_{12}$ for cognition. Cochrane Database Syst Rev, CD004326.

Malouf R \& Grimley EJ (2003) The effect of vitamin $B_{6}$ on cognition. Cochrane Database Syst Rev, CD004393.

Manders M, de Groot LC, van Staveren WA, Wouters-Wesseling W, Mulders AJ, Schols JM \& Hoefnagels WH (2004) Effectiveness of nutritional supplements on cognitive functioning in elderly persons: a systematic review. J Gerontol A Biol Sci Med Sci 59, 1041-1049.

Marcheselli VL, Hong S, Lukiw WJ, et al. (2003) Novel docosanoids inhibit brain ischemia-reperfusion-mediated leukocyte infiltration and pro-inflammatory gene expression. $J$ Biol Chem 278, 43807-43817.

Melzer D, Ely M \& Brayne C (1997) Cognitive impairment in elderly people: population based estimate of the future in England, Scotland, and Wales. BMJ 315, 462.

Miller ER 3rd, Pastor-Barriuso R, Dalal D, Riemersma RA, Appel LJ \& Guallar E (2005) Meta-analysis: high-dosage vitamin E supplementation may increase all-cause mortality. Ann Intern Med 142, 37-46.

Morris MC, Evans DA, Bienias JL, Tangney CC, Bennett DA, Wilson RS, Aggarwal N \& Schneider J (2003) Consumption of fish and $n-3$ fatty acids and risk of incident Alzheimer disease. Arch Neurol 60, 940-946.

Morris MC, Evans DA, Bienias JL, Tangney CC \& Wilson RS (2002) Vitamin E and cognitive decline in older persons. Arch Neurol 59, $1125-1132$.

Mukherjee PK, Marcheselli VL, Serhan CN \& Bazan NG (2004) Neuroprotectin D1: a docosahexaenoic acid-derived docosatriene protects human retinal pigment epithelial cells from oxidative stress. Proc Natl Acad Sci USA 101, 8491-8496.

O’Brien JT, Erkinjuntti T, Reisberg B, Roman G, Sawada T, Pantoni L, Bowler JV, Ballard C, DeCarli C, Gorelick PB, Rockwood K, Burns A, Gauthier S \& DeKosky ST (2003) Vascular cognitive impairment. Lancet Neurol 2, 89-98.

Perkins AJ, Hendrie HC, Callahan CM, Gao S, Unverzagt FW, Xu Y, Hall KS \& Hui SL (1999) Association of antioxidants with memory in a multiethnic elderly sample using the third national health and nutrition examination survey. Am J Epidemiol 150, 37-44.

Perrig WJ, Perrig P \& Stahelin HB (1997) The relation between antioxidants and memory performance in the old and very old. $J \mathrm{Am}$ Geriatr Soc 45, 718-724.

Rodriguez-Martin JL, Qizilbash N \& Lopez-Arrieta JM (2001) Thiamine for Alzheimer's disease. Cochrane Database Syst Rev, CD001498.

Rojas CV, Martinez JI, Flores I, Hoffman DR \& Uauy R (2003) Gene expression analysis in human fetal retinal explants treated with docosahexaenoic acid. Invest Ophthalmol Vis Sci 44, 3170-3177.

Selhub J, Bagley LC, Miller J \& Rosenberg IH (2000) B vitamins, homocysteine, and neurocognitive function in the elderly. Am J Clin Nutr 71, 614S-620S.

Soderberg M, Edlund C, Kristensson K \& Dallner G (1990) Lipid compositions of different regions of the human brain during aging. $J$ Neurochem 54, 415-423.

Soderberg M, Edlund C, Kristensson K \& Dallner G (1991) Fatty acid composition of brain phospholipids in aging and in Alzheimer's disease. Lipids 26, 421-425.

Suzuki H, Hayakawa S \& Wada S (1989) Effect of age on the modification of brain polyunsaturated fatty acids and enzyme activities by fish oil diet in rats. Mech Ageing Dev 50, 17-25. 
Suzuki H, Park SJ, Tamura M \& Ando S (1998) Effect of the longterm feeding of dietary lipids on the learning ability, fatty acid composition of brain stem phospholipids and synaptic membrane fluidity in adult mice: a comparison of sardine oil diet with palm oil diet. Mech Ageing Dev 101, 119-128.

Tabet N, Birks J \& Grimley Evans J (2000) Vitamin E for Alzheimer's disease. Cochrane Database Syst Rev, CD002854.

Uauy R, Hoffman DR, Peirano P, Birch DG \& Birch EE (2001) Essential fatty acids in visual and brain development. Lipids 36, $885-895$.

Uauy R \& Valenzuela A (2000) Marine oils: the health benefits of $n-3$ fatty acids. Nutrition 16, 680-684.
United Nations (2001) World Population Prospects, the 2000 Revision, Volume 1: Comprehensive Tables. New York: United Nations.

Vermeer SE, Prins ND, den Heijer T, Hofman A, Koudstaal PJ \& Breteler MM (2003) Silent brain infarcts and the risk of dementia and cognitive decline. $N$ Engl J Med 348, 1215-1222.

Wald DS, Law M \& Morris JK (2002) Homocysteine and cardiovascular disease: evidence on causality from a meta-analysis. $B M J$ 325, 1202.

World Health Organization/Tufts University (2002) Keep Fit for Life: Meeting the Nutritional Needs of Older Persons. Geneva: WHO. 